\title{
Educação Ambiental Pela Implantação de uma Horta Orgânica em uma Escola Rural no Município de Ijui, RS
}

\author{
Environmental Education by Implantation of a Vegetable Garden In a Rural School In \\ Ijui - RS \\ Angela Maria Maboni Sansonovicz ${ }^{1}$; Cibele Rosa Gacioli \\ ${ }^{1}$ Economista, Especialista em Educação Ambiental, UFSM, Santa Maria (RS), Brasil. \\ E-mail: angelamsans@gmail.com (autora) \\ ${ }^{2}$ Engenheira Florestal e Doutora em Engenharia Florestal pela Universidade Federal de Santa Maria, E- \\ mail: cibelegracioli@gmail.com (orientadora)
}

\section{Resumo}

A busca por uma vida mais saudável pressupõe, entre outras condições, o consumo de produtos de boa qualidade. Essa constatação tem levado a uma crescente expansão do consumo de alimentos produzidos sem o emprego de agrotóxicos. A agricultura orgânica como alternativa à sustentabilidade se caracteriza pela conservação do agroecossistema, respeitando os seus ciclos naturais e o equilíbrio biológico. O objetivo desseartigo é apresentar uma discussão inicial acerca do crescimento da produção orgânica na Escola Estadual Souza Lobo de Ensino Fundamental no município de Ijui, RS. Para tanto, foi necessário realizar uma pesquisa bibliográfica sobre agroecologia, agricultura orgânica e sustentabilidade. Com a prática da construção da horta orgânica na escola, os alunos aprenderam como cuidar do Meio Ambiente.

Palavras-chave: Agricultura orgânica. Agroecologia. Sustentabilidade.Equilíbrio biológico.

\begin{abstract}
The search for a healthier life requires, among other conditions, the consumption of good quality products. This finding has led to an increasing expansion of consumption of food produced without the use of pesticides. Organic farming as an alternative to sustainability is characterized by the conservation of agro ecosystem, respecting their natural cycles and the biological balance. The purpose of this monograph is to present an initial discussion on the growth of organic production in the State School Souza Lobo Elementary School in the city of Ijui. Therefore it was necessary to perform a literature search on agroecology, organic agriculture, sustainability. With this practice, which was developed in the school the students learned how to take care of the environment.
\end{abstract}

Keywords: Organic agriculture. Agroecology.Sustainability.Biological equilibrium 


\section{Introdução}

Na educação ambiental o solo vai ser analisado como local de moradia do homem, onde construímos casas, estradas, fábricas, áreas de lazer, entre outros. Mas também como ambiente que recebe e acumula nossos resíduos, interferindo na qualidade de vida, das pessoas e dos animais. O desafio da gestão ambiental sustentável para as futuras gerações é encontrar o equilíbrio entre os objetivos humanos e os impactos sobre o meio ambiente preservando o ecossistema, respeitando a vida, através da análise fundamentalista, ao entendimento do processo de educação com princípios pedagógicos entre a teoria e a prática. Salientar a importância da agricultura orgânica, com aproveitamento de todos os resíduos que as árvores do bosque da escola produzem. Como as folhas que caem e outros resíduos de madeira existente, onde são colocados em um espaço e, após, são misturados com a terra para tornar ela mais fértil. A construção da horta na escola tem como objetivo principal a motivação das crianças e jovens pelos temas ambientais, visando assegurar condições ao desenvolvimento socioeconômico, e à proteção da dignidade da vida humana para toda a comunidade escolar e sua educação fora da escola, para a vida.

O saber ambiental, subentendido como a formação de um novo saber e a integração interdisciplinar do conhecimento. Esse conhecimento teórico e prático, orientado para articulação das relações sociedade-natureza. Esse conhecimento não se esgota na extensão dos paradigmas da ecologia e nem tem limites a um determinado componente ecológico, nos paradigmas dos dias de hoje do conhecimento. O saber ambiental vai além das "ciências ambientais", que foi constituída pela antropologia ecológica, ecologia urbana, saúde, psicologia, economia e engenharia ambiental, e vai além abre um campo dos valores éticos, dos conhecimentos práticos e do saber tradicional.

Os processos ecológicos, econômicos, tecnológicos e culturais que confluem num sistema socioambiental são conformados pelos interesses e racionalidades de atores sociais e organizações institucionais diversos. O saber ambiental é constituído não só pela confluência de disciplinas científicas estabelecidas, mas pela emergência de um conjunto de saberes teóricos, técnicos e estratégicos, atravessados por estratégias de poder no saber (LEFF, 2012, p. 147).

Para Leff (2012), o saber ambiental está em processo de gestação, tentando se legítimar, teórico e prático, este saber passa pelo processo transdisciplinar, mudança de paradigma; integrando fenômenos naturais e sociais articulando processos materiais com especificidade ontológica e epistemológica. Trata-se de um processo teórico que se dá através de movimentos sociais e mudanças institucionais que incidem na concretização do conceito de ambiente, esse ambiente em que vivemos, na transformação das práticas pedagógicas onde é assimilado o saber, e nas práticas de ensino onde trabalhamos. O saber ambiental emergente propõe a reconstrução da subjetividade e dos sujeitos da história, diferença do ser e da autoridade dos indivíduos, suas diversidades, suas memórias, novas formas de posicionamento no mundo são geradas.

O Brasil está se consolidando como um grande produtor e exportador de alimentos orgânicos, com mais de 15 mil propriedades certificadas e em processo de transição $75 \%$ pertencentes a agricultores familiares. O governo brasileiro está apoiando a produção orgânica, oferecendo linhas de financiamento especiais para o setor e incentiva projetos de transição de lavouras tradicionais para a produção orgânica. Com essa grande importância que a produção orgânica vem assumindo no mercado de alimentos exige regulamentação que assegure ao consumidor a garantia de que está adquirindo um item que obedece ás normas legais estabelecidas para o produto orgânico. A Lei $\mathrm{n}^{\circ}$ 10.831/03 (BRASIL, 2003) dispõe sobre o sistema orgânico de produção agropecuária. Ela diz o seguinte: 
Art. $1^{\circ}$ Considera-se sistema orgânico de produção agropecuária todo aquele em que se adotam técnicas específicas, mediante à otimização do uso dos recursos naturais e sócio econômicos disponíveis e o respeito á integridade cultural das comunidades rurais, tendo por objetivo a sustentabilidade econômica e ecológica, a maximização dos benefícios sociais, a minimização da dependência de energia não renovável, empregando, sempre que possível, métodos culturais, biológicos e mecânicos, em contraposição ao uso de materiais sintéticos, a eliminação do uso de organismos geneticamente modificados e radiações ionizantes, em qualquer fase do processo de produção, processamento, armazenamento, distribuição e comercialização, e a proteção do meio ambiente (BRASIL, 2003).

O Ecossistema é uma unidade básica com a qual lidamos, pois inclui tanto os organismos como o ambiente não vivente, cada qual influenciando as propriedades do outro, e ambos necessários para a manutenção da vida tal como a temos no mundo (VIDYA, 1999).

Um ecossistema é estruturado por quatro constituintes que são: substâncias abióticas (água, gás carbônico, solo, etc.), produtores (plantas), consumidores (aves, mamíferos, anelídeos, insetos, etc.) e decompositores (fungos, bactérias e vírus). Com o envolvimento desses quatro componentes, ocorrem dois processos, que são: a taxa de transformação e transferência de energia (sobre o ponto de vista da física a energia não flui, ela se transforma e se transfere) e a ciclagem dos nutrientes, de forma contínua e essencial para dar sustentabilidade ao ecossistema (VIDYA, 1999).

O manejo na agricultura orgânica valoriza o uso eficiente dos recursos naturais não renováveis, bem como o aproveitamento dos recursos naturais renováveis e dos processos biológicos alinhados á biodiversidade, ao meio ambiente, ao desenvolvimento econômico e à qualidade de vida humana (BROSE, 1999). Esse tipo de agricultura enfatiza o uso e a prática de manejo sem o uso de fertilizantes sintéticos de alta solubilidade e agrotóxicos, além de reguladores de crescimento e aditivos sintéticos para a alimentação animal. Sendo que esta prática agrícola preocupa-se com a saúde dos seres humanos, dos animais e das plantas, entendendo que seres humanos saudáveis são frutos de solos equilibrados e biologicamente ativos, adotando técnicas integradoras e apostando na diversidade de culturas. Apoiando-se em quatro fundamentos básicos: - respeito á natureza, reconhecimento da dependência de recursos naturais não renováveis; - a diversificação de culturas, leva ao desenvolvimento de inimigos naturais, sendo item chave para a obtenção de sustentabilidade; - o solo é um organismo vivo, o manejo do solo propicia oferta constante de matéria orgânica (adubos verdes, cobertura morta e composto orgânico), resultando em fertilidade do solo; - independência dos sistemas de produção, ao substituir insumos tecnológicos e agroindustriais (SAQUETet al, 2010).

\section{Metodologia}

A escola na qual foi feita essa pesquisa, teve início das suas atividades em março de 1961, com 53 anos de existência. Sua área total de terra é quatro hectares, situada na linha 6 oeste do município de Ijuí, RS. Desses quatro hectares possui a sede da escola com três prédios principais, um composto por duas salas de aula e outro com secretaria, refeitório e sala da direção e professores.

Possui um bosque enorme, onde foi construída a horta orgânica, o restante da área é composto por quadra de esporte, área de lazer, espiral de ervas, relógio medicinal, pracinha e uma área coberta por uma mata nativa com árvores exóticas, nesta mata nativa possui uma trilha ecológica.Nesta trilha ecológica são desenvolvidos vários tipos de atividades com os alunos da escola e visitantes. Cada atividade foi organizada em paradas, e em cada parada são feitas observações; até chegar a um olho de água com uma vertente no meio da mata. Essa trilha ecológica é uma atividade importante que a escola possui, 
pelo fato de ser local que recebe visitas de estudos de várias escolas do município de Ijuí,RS, tanto das escolas particulares com alunos de pré-escola até o ensino médio, como as escolas públicas estaduais e municipais, esta trilha serve de modelo de estudo ecológico e de preservação do meio ambiente para o município de Ijuí, RS.

\section{Resultados e Discussão}

\subsection{Trilha ecológica}

A trilha foi adaptada para diferentes tipos de públicos e é realizada sob a supervisão de técnicos qualificados que explicam os detalhes e características da fauna e flora encontradas no local, tendo como objetivo a disseminação da educação para conservação da natureza. Ao longo da trilha, há vários pontos indicados para paradas, que são usados para ensinamentos lúdicos, como o som das aves, a temperatura da floresta e detalhes da flora, foi possível observar até mesmo árvores raras ou em algum nível de ameaça de extinção. Além da flora, no início das trilhas na "Calçada da Fauna", foi possível observar as pegadas de alguns dos animais que ocorrem na mata, como o cachorro-do-mato, gatodo-mato, jaguatirica, entre vários outros. O principal objetivo é que os jovens e as crianças se tornem multiplicadores do conhecimento aprendido no passeio. A visita torna os visitantes multiplicadores da ideia da conservação da biodiversidade e também faz com que os outros proprietários de áreas naturais percebam como a conservação dos recursos naturais e os serviços ecossistêmicos são importantes para a sobrevivência de uma sociedade.

\subsection{Espiral de ervas}

Uma espiral de ervas é simples e pode ser importante no seu jardim. É um elemento muito importante para o design de jardins permaculturais. Ela acomoda todas as ervas básicas, portanto o acesso fácil. $\mathrm{O}$ padrão espiralado, muito comum na natureza, foi reproduzido em um pequeno monte de terra, contemplando aspectos como diversidade, consórcios, efeito de bordas,microclimas e drenagem. Com aproximadamente 1.6 metros de diâmetro na base ealtura de 1 a 1.3 metros, este canteiro oferece inúmeras possibilidades para o enriquecimento da dieta familiar. É importante que se conheça as espécies que se pretende cultivar e sua necessidade. Desta forma, pode-se escolher o local mais apropriado para as plantas de acordo com o microclima dentro da espiral. O professor, os alunos e o funcionário da escola fizeram a construção da espiral de ervas. Plantaram as ervas básicas que servem de tempero e as suculentas, e os alunos estão auxiliando com as regas.

\subsection{Relógio Medicinal}

Esta metodologia relaciona conhecimentos sobre a função dos principais órgãos do corpo humano e onde eles se localizam no organismo, promovendo o aprendizado e a reflexão, tornando os indivíduos sujeitos da sua própria saúde, responsáveis pelas suas escolhas e hábitos de vida. Propõe uma forma de tratamento baseada na observação de cada indivíduo e nos primeiros cuidados que podem ser tomados para evitar transtornos de saúde. Os objetivos do projeto foram: promover a educação em saúde, proporcionando o conhecimento da localização e do funcionamento dos órgãos do corpo humano, oportunizando uma reflexão sobre os hábitos de vida, as escolhas comportamentais e os cuidados básicos de saúde, utilizando as plantas medicinais com segurança. Através do "Relógio do Corpo Humano" e as plantas medicinais foi possível desenvolver atividades multidisciplinares nas áreas de: Promoção em saúde, alimentação saudável e segurança alimentar, educação ambiental e preservação ambiental, conhecimento do corpo humano (autoconhecimento), Identificação segura das plantas medicinais, aromáticas e 
condimentares e suaspotencialidades de utilização, produção de plantas limpas, sadias, de forma orgânica. Construção de hortos Escolares (estimula o envolvimento de várias disciplinas, matemática, ciências, português, geografia...).

Importante destacar que a metodologia aconselha a não trabalhar com muitas espécies de plantas para cada órgão, por não ser pedagógico e didático e por poder gerar confusões. Poderão ser utilizadas outras plantas para compor o relógio do corpo humano e as plantas medicinais, desde que sejam bastante comuns para a comunidade onde ele se localizará e desde que seja realizada uma pesquisa aprofundada sobre a validação científicadestas plantas para o órgão referente.

\subsection{Construção da horta orgânica}

A ideia da agricultura orgânica vem crescendo nos últimos anos vem ganhando grande importância no cenário agrícola nacional e internacional. Foi no Século XX que ocorreram os maiores avanços na indústria e na ciência, o que teve forte impacto na agricultura (SAQUETet al, 2010).

Durante a fase de expansão e tecnificação agrícola, a preocupação ambiental foi muito pequena, possibilitando que ocorressem grandes impactos ambientais e trazendo graves implicações sociais. Este contexto impulsionou o crescimento da linhade agricultura chamada "Agricultura Orgânica". Esta não é uma ideia recente, pois se pode considerar comoorgânica praticamente toda a agricultura realizada com baixa tecnificação ou por quem não tem acesso a insumos. Por muitos anos, a ideia de agricultura orgânica foi associada ao movimento "hippie", a sonhadores idealistas ou atitude de protesto e porisso sofria restrições no meio acadêmico, científico e mesmo entre os agricultores.

Quando a sociedade passou a ter conhecimento do potencial malefício à saúde causada pelos agrotóxicos, formou-se uma onda mundial de rejeição a alimentos produzidos com estes insumos. Foi esta força de mercado que conseguiu erguer todo o movimento que assistimos nos dias atuais. As pessoas querem consumir produtos livres de agrotóxicos e estão dispostas á pagar um pouco mais caro para isso. Interessados em atender este mercado, os produtores interessaram-se em converter suas áreas de produção e buscar técnicas apropriadas.

Agricultura orgânica é o sistema de produção que não usa fertilizantes sintéticos, agrotóxicos, reguladores de crescimento ou aditivos sintéticos para a alimentação animal.

Conforme Carvalho (1980), a quantidade de matéria orgânica vegetal formada e decomposta por ano sobre a superfície da terra é igual a 55 bilhões de toneladas. Dessas $90 \%$ passa pouco a pouco ao estado gasoso, enquanto os $10 \%$ se transformam em minerais e compostos orgânicos intermediários. Assim o comportamento do fenômeno vida como um circuito fechado onde a matéria orgânica surge fabricada, numa síntese, a partir do bióxido de carbono e água (inorgânicos) elaborada pelos vegetais (fotossíntese), como já vimos. Este fenômeno é caracterizado pela decomposição desta mesma matéria orgânica em seus principais constituintes elementares, carbono, hidrogênio, oxigênio e nitrogênio.

A agricultura orgânica é o sistema de produção que exclui o uso de fertilizantes sintéticos de alta solubilidade, agrotóxicos, reguladores de crescimento e aditivos para a alimentação animal, compostos sinteticamente. Sempre que possível baseia-se no uso de estercos animais, rotação de culturas, adubação verde, compostagem e controle biológico de pragas e doenças. Busca manter a estrutura e produtividade do solo, trabalhando em harmonia com a natureza.

Neste contexto, as concepções que a maioria dos alunos tem em relação ao ambiente em que vivem, são formadas a partir de influências múltiplas e que se expressam em várias situações. Como exemplo, verifica-se que entre os seres vivos, os alunos interessam-se, predominantemente, pelos animais de estimação, pelas plantas ornamentais ou, ainda, por aqueles que possam ser explorados economicamente, como se os demais fossem intrusos e devessem ser eliminados. Ignora-se, assim, muitas vezes, as relações desses no ecossistema e, portanto, na garantia da própria vida do Planeta Terra. A capoeira, o mato, as chamadas plantas invasoras de lavouras e os animais silvestres são 
considerados maus e nocivos ao homem. No entanto, são essenciais para a produção de oxigênio, refrigeração do planeta e ciclagem da matéria, entre outras relações estabelecidas.

Num ecossistema natural, todo este processo ocorre num mesmo espaço físico, onde quanto maior a ciclagem de nutrientes melhor será sustentabilidade. Nesse ecossistema, praticamente, entra apenas a energia solar, podendo também ás vezes, entrar parte da água e do gás carbônico necessário á sua manutenção.

$\mathrm{Na}$ visão agroecológica, existe uma ideia de que as lavouras ou pomares são ecossistemas nos quais os processos ecológicos, como ciclos de nutrientes, interação predador, competição, comensalismo e sucessões ecológicas, também aparecem. Portanto, são denominados "Agroecossistemas".

Nesta visão, tem uns pesquisadores das ciências agrícolas começam a ver uma lavoura como um tipo particular de ecossistema, um "agroecossistema". E neste contexto a horta está inserida, ao preparar ela o homem elimina grande parte dos seres vivos do local e coloca a semente de uma única espécie vegetal (produtor). O equilíbrio não pode ser restabelecido devido á estrutura de vida da humanidade. Há necessidade de retirar da área cultivada a parte que será utilizada pelo homem que habita as cidades. Portanto, seus detritos e dejetos são acumulados de forma concentrada em determinados locais, poluindo o ambiente, não retornando mais aquela área, impedindo, assim, a ciclagem dos nutrientes. Então, constantemente será necessário fornecer nutrientes ao "agroecossistema", para garantir a retirada da sua produção, na velocidade solicitada,onde é chamado de sistema agrícola (VIDYA, 1999).

A escola de ensino fundamental foi selecionada para eu fazer esse trabalho pela característica principal de ter alunos com afinidades no meio agrícola. Para esta atividade foi organizado um mutirão, para os quais foram convidados todos os alunos da $6^{\mathrm{a}}, 7^{\mathrm{a}}$ e $8^{\mathrm{a}}$ série; o professor de agroecologia e o funcionário da escola.

Iniciou-se a construção da horta, definido o tamanho da horta que é de doze metros de comprimento por oito metros de largura, os canteiros medindo um metro e dez centímetros de largura para facilitar o manuseio das plantas e para o braço alcançar; de um lado para outro, onde serão construídos quatro canteiros de fora a fora.

Iniciando os trabalhos no primeiro momento os pais vieram na escola e juntamente com os alunos e professores e funcionários fizeram a terraplenagem com o trator. Feito isso os alunos, os professores e o funcionário com enxadas, enxadões, rastelo, garfo; pá e carrinho de mão, e foram virando a terra. Depois da terra virada todos os envolvidos foram ao bosque e trouxeram folhas e pedaços de madeira podre misturando na terra da horta.

Após os canteiros prontos os alunos fizeram a adubação orgânica, seguida de uma espera para começar a plantar as mudas, e semear outras. Também esses alunos construíram a composteira em um espaço no mesmo cercado da horta para aproveitar resíduos de folhas das arvores após as podas para tornar em terra boa novamente no cultivo das hortaliças, lugar este que os alunos colocarão todos os resíduos para se tornar adubo orgânico.

Implantar uma horta orgânica, desde a escolha do local com sugestão de lay-outs, detalhando as ferramentas e utensílios que serão necessários, receber luz direta do sol por no mínimo 5 horas diárias e a direção dos canteiros norte-sul, ou voltados para o norte para aproveitar melhor o sol.

Para construir a composteira foi comprado tijolos, os alunos o funcionário e o professor fizeram a massa para assentar os tijolos e deram início na construção da composteira.

Com essa prática envolvendo os alunos na construção da horta na escola, pode-se desenvolver a criatividade deles para preservar o meio ambiente; utilizando resíduos de folhas das arvores após as podas para tornar em terra boa novamente no cultivo das hortaliças. Todo esse material foi "compostado" (colocado para curtir) para posteriormente ser transformado em composto orgânico que é essencial para o desenvolvimento dos vegetais. O processo de compostagem nada mais é o resultado do trabalho dos micro organismos (bactérias) que irão transformar todo o material orgânico em húmus, material 
rico em macro e micro nutrientes e com vida. Esse composto será o melhor aditivo orgânico que sua horta irá receber.

Para manter o processo em funcionamento não deixe secar, mas não deixe encharcar e mantenha-o arejado, retirando sempre que possível o material já processado pelo fundo do tambor. Você irá identificar facilmente o material pronto, pois será muito parecido com terra preta tanto na textura quanto no aroma.

\section{Conclusão}

Sustentabilidade é o caminho do equilíbrio em que o social, o econômico e o ambiental se somam para vivermos em uma sociedade melhor para todos. Para que algo seja considerado "sustentável", deve atender aos três pilares sendo economicamente viável, socialmente justo, e ambientalmente adequado. Tudo isso é relacionado ao que acontece no mundo de hoje e com o nosso dia a dia. O pensar certo é tomado em si mesmo e dele se fala ou uma prática que puramente se descreve, mas algo que se faz e que se vive enquanto dele se fala com a força do testemunho. Pensar certo implica a existência de sujeitos que pensam mediados por objeto ou objetos sobre que incide o próprio pensar dos sujeitos, é um ato comunicante, e quem pensa tem que entender o que pensa. A tarefa coerente do educador que pensar certo, é exercendo como ser humano a irrecusável prática de interagir e desafiar o educando com quem se comunica e a quem comunica, produzir sua compreensão do que vem sendo comunicado.

Os discentes e os docentes têm que conviver de uma maneira onde os saberes se cruzam e viram sabedoria, desenvolvendo a capacidade de aprender e de ensinar. $O$ professor é o mediador do conhecimento e que ele acontece somente numa relação de interação entre o objeto cognoscente. Neste contexto o professor de história que desenvolve a disciplina de agroecologia na prática da construção da horta orgânica está inserido, envolvendo a prática com todos os alunos.

A construção do espiral de ervas, do relógio medicinal com doze ervas diferentes e da horta orgânica na escola servirá como base para as disciplinas que os alunos da $6^{\mathrm{a}}, 7^{\mathrm{a}} \mathrm{e}$ $8^{a}$ série estudam em geografia e as tecnologias da agricultura na disciplina de agroecologia, na sua prática no contato com o solo. Onde os alunos aprenderam com essas aulas práticas como cuidar do meio ambiente, e aproveitar os resíduos orgânicos, para cuidar da saúde.

Também as aulas ministradas nas paradas da trilha ecológica, para os jovens e as crianças, tornando eles multiplicadores do conhecimento e formadores da ideia da conservação da biodiversidade e também faz com que os outros proprietários de áreas naturais percebam como a conservação dos recursos naturais e os serviços ecossistêmicos são importantes para a sobrevivência de uma sociedade.

\section{Referências}

BRASIL. Lei $\mathbf{n}^{\mathbf{0}} 10.831$, de 23 de dezembro de 2003. Dispõe sobre a agricultura orgânica e dá outras providências. Disponível em: <http:// www.planalto.gov.br/ccivil_03/leis/2003/110.831.htm>. Acesso em: 20 jan. 2015.

BROSE, M. Agricultura familiar, desenvolvimento local e políticas públicas; Santa Cruz do Sul: Ed. EDUNISC, 1999.

CARVAlHO, B. A. Ecologia Aplicada ao Saneamento Ambiental; Rio de Janeiro: ABES, 1980. 
LEFF, Enrique. Saber ambiental: sustentabilidade, racionalidade, complexidade, poder. Tradução de Lúcia MathildeEndlich Orth. 9. ed. Petrópolis, Rio de Janeiro: Vozes, 2012.

SAQUET, M. A.et al. A agroecologia como estratégia de inclusão social e desenvolvimentoterritorial. In: SAQUET, M. A; SANTOS, R. A (Orgs). Geografia agrária, território edesenvolvimento. $1^{\text {a }}$ Ed. São Paulo: Expressão Popular, 2010.

VIDYA, Centro Universitário Franciscano. Saúde, Educação e Meio Ambiente, Santa Maria, v. 18, n. 32, jul./dez. 1999. 